\title{
Effect of aerobics on weight and fat mass loss in adult women: Systematic review and meta-analysis
}

\author{
Petra Hiklová and Aleš Gába* \\ Faculty of Physical Culture, Palacký University Olomouc, Olomouc, Czech Republic
}

Copyright: (C) 2019 P. Hiklová and A. Gába. This is an open access article licensed under the Creative Commons Attribution License (https://creativecommons.org/licenses/by/4.0/).

Background: Aerobics (AE) is an attractive type of aerobic exercise and can be considered as an appropriate intervention strategy for weight loss. However, results of clinical trials are not consistent due to high variability in relation to the type of AE and duration of intervention. Objective: The objective was to investigate the effect of AE on weight and fat mass loss in adult women. Methods: Of the total number of 243 studies, the final analysis included seven clinical trials with a pooled sample size of 242 females. Results: Although the results confirmed a significant overall effect on weight loss $(-1.97 \mathrm{~kg}, 95 \%$ confidence interval [ $-3.72,-0.23], p=.03)$, an effect on fat mass loss was not confirmed $(-2.62 \%, 95 \%$ confidence interval $[-5.53,0.29], p=.08)$. It was further observed that traditional AE and longer interventions have a greater effect on reducing body weight and fat mass compared with aqua $\mathrm{AE}$ and interventions shorter than 10 weeks. Conclusions: In conclusion, AE seems to be an effective intervention for weight loss in women, but the type of $\mathrm{AE}$ and the duration of the intervention should be considered.

Keywords: exercise, weight loss, adiposity, obesity

\section{Introduction}

Obesity has accompanied the human population since historical times. While at the beginning of the twentieth-century obesity was merely a problem of developed countries (Caballero, 2007), currently the number of obese individuals has dramatically increased around the globe, and this non-communicable disease is referred to as a pandemic (Swinburn et al., 2019). Since 1980, the number of overweight adults has risen by almost 1.2 billion ( $\mathrm{Ng}$ et al., 2014). This increase is confirmed by the constantly growing mean body mass index (BMI) in almost all countries of the world. During the past decade, the average increase in the BMI value in women was $0.5 \mathrm{~kg} / \mathrm{m}^{2}$ (Finucane et al., 2011).

Obese women are at a higher risk of associated diseases compared with men (Hu, 2003). These diseases include for example type II diabetes mellitus, dyslipidaemia, obstructive sleep apnoea, hypertension, and cardiovascular diseases (Blair \& Church, 2004; Li \& Cheung, 2009). Severe obesity is treated by bariatric

\footnotetext{
* Address for correspondence: Aleš Gába, Department of Natural Sciences in Kinanthropology, Faculty of Physical Culture, Palacký University Olomouc, třída Míru 117, 77111 Olomouc, Czech Republic. E-mail: ales.gaba@upol.cz
}

surgery or pharmacotherapy (Angrisani et al., 2015; Wadden et al., 2005). Other methods of treatment include psychotherapy, dietary restrictions, and physical activity (PA), which are non-invasive, financially affordable (Blair \& Church, 2004; Esposito et al., 2003; Tanofsky-Kraff et al., 2010), and their effect has been confirmed for both combined (Melam, Alhusaini, Buragadda, Kaur, \& Khan, 2016) and individual application (Park et al., 2003).

PA is used as a means of intervention especially because a number of prospective studies confirm its protective effect on adiposity (Fogelholm \& Kukkonen-Harjula, 2000; Kay \& Fiatarone Singh, 2006). However, PA intervention should reflect the current health condition and degree of obesity (Ball, Owen, Salmon, Bauman, \& Gore, 2001; Petersen, Schnohr, $\&$ Sorensen, 2004). The result of the intervention is influenced by a number of factors such as its duration. This modifiable factor affects not only the effectiveness of the intervention but has a great influence on the participants' adherence to the intervention programme (Jakicic \& Otto, 2005). Other factors include the intensity and frequency of intervention PA. For an overweight or obese individual, appropriate activity is low-intensity exercise carried out over a longer period of time (Donnelly et al., 2003). 
The recommended duration of PA for a slight weight loss in adults should be at least 150 to 250 minutes of moderate-intensity PA per week and should be combined with appropriate dietary restrictions. In order to achieve a significant weight loss, it is recommended to increase PA above 250 minutes per week (Donnelly et al., 2009). PA has a positive effect on increasing energy expenditure and reducing the amount of fat mass (FM), is an important means of prevention of many non-communicable diseases, and offers a wide range of additional health benefits (Ewald, Attia, \& McElduff, 2014). Obese individuals are recommended low to moderate intensity PA. Appropriate activities for these individuals include walking, cycling, swimming, and other activities in the aquatic environment (Frank, Andresen, \& Schmid, 2004; Gappmaier, Lake, Nelson, $\&$ Fisher, 2006). An attractive type of aerobic exercise for women is aerobics (AE). In the context of secondary obesity prevention, an appropriate modification of $\mathrm{AE}$ is aqua $\mathrm{AE}$ (Wing \& Phelan, 2005). The results of intervention studies addressing the influence of $\mathrm{AE}$ on weight and FM loss in women are not consistent in terms of their conclusions, especially due to their high variability in relation to the type of $\mathrm{AE}$ and duration of intervention. For this reason, the main objective of the present study was to assess the overall effect of $\mathrm{AE}$ on weight and FM loss using a systematic review of available scientific evidence, and to conduct a synthesis by means of a meta-analysis.

\section{Methods}

The present systematic review was devised in line with the Preferred Reporting Items for Systematic Reviews and Meta-analysis (PRISMA) statement (Moher, Liberati, Tetzlaff, \& Altman, 2009).

\section{Search strategies}

The search included the Medline and SPORTDiscus databases covering a period from January 2000 to April 2018. The search strategy was arranged in three sets and focused on the target population (adult women), intervention (various forms of $\mathrm{AE}$ ) and exposure outcomes (weight and FM loss). Table 1 shows an example of a search strategy in the Medline database (via Ovid). The main part of the search strategy included the Medical Subject Heading (MeSH) terms. Subsequently, selected free-text terms were included in the search strategy in order to extend the search and cover specific areas of interest. The search strategy was limited to human participants and the English language. The search results were imported into the EndNote programme (Version X7; Thomson Reuters, San Francisco, CA, USA), any duplicates were deleted, and an online Excel spreadsheet was produced for screening purposes. The final database included several unique identifiers for each study and several pieces of bibliographic information (study title, authors, year of publication, abstract, journal title, and article identifier).

In the first stage, the title and abstract of the studies were screened by two independent evaluators (P. H. and A. G.). The studies were divided into three groups: relevant, irrelevant, and potentially relevant studies. In the case of potentially relevant studies, their full-texts were analysed and then the studies were included or excluded. In the event of a disagreement between the evaluators concerning the relevance of a particular study, the final decision as to inclusion or exclusion was made by a third person. In addition to searching the databases mentioned above, the authors performed a hand search of the list of references of all relevant studies included in the review. In this way, an additional relevant study was identified (Figure 1).

\section{Inclusion and exclusion criteria}

The review included only randomized clinical trials (RCT) or clinical trials without control groups involving adult women older than 18 years. The upper age limit was not defined. The review did not include studies with mixed groups for which relevant data were not obtained even after contacting the corresponding authors. The review included studies involving healthy women, women with diagnosed overweight or obesity, and women with a sedentary lifestyle. Studies involving pregnant participants were excluded. The final sample included studies whose intervention PA was traditional $\mathrm{AE}$ or modified $\mathrm{AE}$ (e.g., step or aqua $\mathrm{AE}$ ) without restrictions as to duration, intensity or frequency. The review included studies that combined AE with dietary restrictions. The duration of intervention was not strictly defined but single load studies were excluded.

\section{Data extraction and risk of bias assessment}

Data extraction from full texts was performed by an investigator (P. H.); the final version of the dataset was checked by a reviewer (A. G.) For the purposes of the meta-analysis, information about changes in body weight or fat mass percentage (FM\%) was extracted. The secondary variables related to the duration of intervention, type of $\mathrm{AE}$, and participants' age and health status. In addition, the basic information about the studies included was extracted (design, country of origin, main objectives, and conclusions), including descriptive characteristics of the participants (average age, age category, initial health status, and size of the intervention group). The authors also focused on information about the intervention programme (duration, 
Table 1

Search strategy for the Medline database (via OVID)
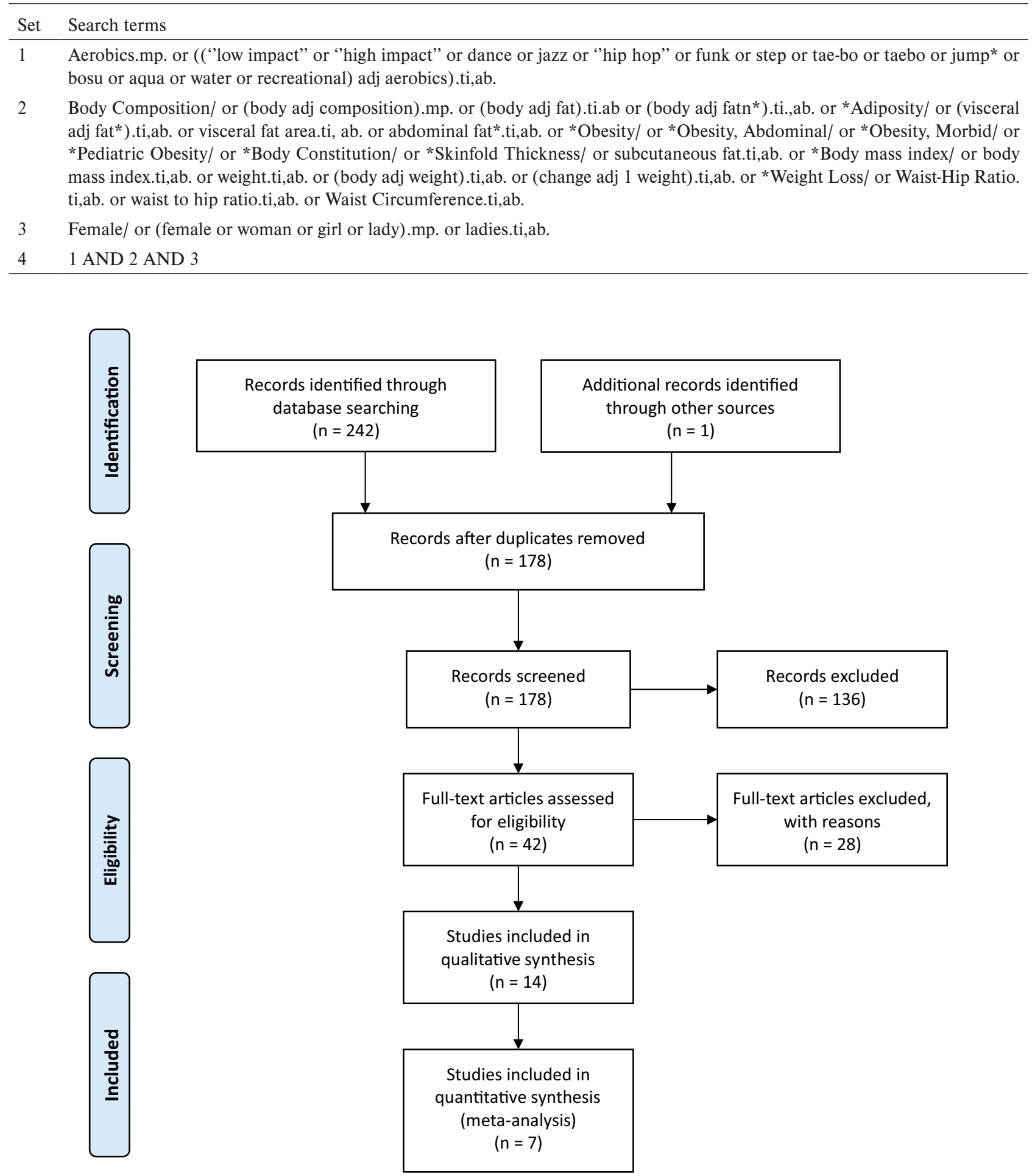

Figure 1. PRISMA flow diagram.

frequency and content of the intervention, type of $\mathrm{AE}$ ), about the method of measurement of the main variables, and about the result of the intervention. Where studies did not include information about the effects of intervention, the corresponding authors were contacted in order to obtain the missing information. Specifically, the corresponding authors of five RCTs were contacted, of whom two provided the necessary information (Araújo et al., 2015; Melam et al., 2016). The risk of bias was analysed for randomized trials 
included in the meta-analysis based on the Cochrane Collaboration's tool for the risk of bias assessment. The risk of bias was rated as low risk, high risk, or unclear risk for each domain (i.e., selection, performance, detection, attrition, and reporting bias).

\section{Statistical processing}

For the calculation of the effect size of the intervention, only RCT studies with available data for metaanalysis were used $(N=7)$. The heterogeneity of the studies was assessed by means of the Cochran's Q-test, and for the assessment of the effect of heterogeneity on the variability of the overall effect, the $I^{2}$ indicator was used. $I^{2}$ values of 25,50 , and 75 were considered to indicate low, moderate and high heterogeneity, respectively (Higgins, Thompson, Deeks, \& Altman, 2003). For the assessment of the overall effect the randomeffects meta-analysis method was used, because in all cases a moderate to high degree of heterogeneity was observed $\left(I^{2}<50 \%\right)$. Similarly, an analysis of subgroups was performed to allow for the effect of the type of $\mathrm{AE}$ and duration of intervention. The results of the meta-analysis are shown graphically as forest plots. Statistical analysis was performed by means of RevMan (Version 5.3; The Nordic Cochrane Centre, Copenhagen, Denmark) software at a level of significance of $\alpha=.05$.

\section{Results}

In the Medline and SPORTDiscus databases, a total of 242 studies were identified based on the search strategy. The hand search of the references of all relevant studies identified one relevant study (Arslan, 2011). After removal of duplicates and exclusion of studies based on predetermined criteria, the final sample included 9 RCTs (Araújo et al., 2015; Arslan, 2011; Jasiński et al., 2015; Kantyka, Herman, Roczniok, \& Kuba, 2015; Kin-Isler \& Kosar, 2006; Melam et al., 2016; Nagle et al., 2007; Novaes et al., 2014; Park et al., 2003) and 5 uncontrolled clinical trials (Duzova et al., 2018; Hallage et al., 2010; Pilch et al., 2017; RuizMontero, Castillo-Rodriguez, Mikalacki, Nebojsa, \& Korovljev, 2014; Said, Lamya, Olfa, \& Hamda, 2017), the overview of which is shown in Table 2.

The final sample included studies published primarily in Europe, Asia, North and South America. On average, the intervention programmes included 36 participants. In one study, the intervention also included men, but they were excluded from the analysis (Kin-Isler \& Kosar, 2006). The average age of the female participants was $40.8 \pm 14.1$ years. Taking into consideration only RCTs, the average age of the female participants was $43.7 \pm 14.3$ years and the average number of participants was 16 . Initially, most of the participants were diagnosed with overweight or obesity. The sample also included women with a sedentary lifestyle, women after menopause, healthy women, or the health status of the participants was not specified.

The most frequently used type of $\mathrm{AE}$ was aqua and step AE followed by traditional AE. Other types of $\mathrm{AE}$ were not included. The most used frequency was 3 times a week for an average duration of 45 minutes. The average duration of intervention was 10 weeks for the age category of $<30$ years, 16 weeks for the age category of 30-45 years, and 15 weeks for women older than 45 years.

Figure 2 shows the overall effect of $\mathrm{AE}$ on bodyweight depending on the type of AE. The overall effect of interventions that included various types of $\mathrm{AE}$ was significant and equalled $-1.97 \mathrm{~kg}(95 \%$ confidence interval (CI) [-3.72, -0.23], $p=.03)$. However, an analysis of studies that included only aqua $\mathrm{AE}$ did not

\begin{tabular}{|c|c|c|c|c|c|c|c|c|c|c|c|c|}
\hline \multirow{3}{*}{$\frac{\text { Study or Subgroup }}{1.1 .1 \text { Aqua aerobic }}$} & \multicolumn{3}{|c|}{ Experimental } & \multicolumn{3}{|c|}{ Control } & \multicolumn{3}{|c|}{ Mean Difference } & \multirow{2}{*}{\multicolumn{3}{|c|}{$\begin{array}{c}\text { Mean Difference } \\
\text { IV, Random, } 95 \% \mathrm{CI}[\mathrm{kg}]\end{array}$}} \\
\hline & Mean $[\mathrm{kg}]$ & $\mathrm{SD}[\mathrm{kg}]$ & Total & Mean [kg] & SD [kg] & Total & Weight & IV, Random, $95 \% \mathrm{Cl}[\mathrm{kg}]$ & Year & & & \\
\hline & & & & & & & & & & & & \\
\hline Nagle (2007) & -6.8 & 3.2 & 22 & -5.6 & 4.7 & 22 & $17.2 \%$ & $-1.20[-3.58,1.18]$ & 2007 & 一 & 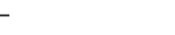 & \\
\hline Araújo (2015) & 0.3 & 7.1 & 9 & 0.3 & 8.2 & 10 & $5.1 \%$ & $0.00[-6.88,6.88]$ & 2015 & & & \\
\hline Jasinski (2015) & 2.3 & 3.7 & 8 & 0.3 & 3.2 & 8 & $12.9 \%$ & $2.00[-1.39,5.39]$ & 2015 & & & \\
\hline Kantyka (2015) & -0.6 & 0.8 & 10 & 0.7 & 1.8 & 11 & $22.6 \%$ & $-1.30[-2.47,-0.13]$ & 2015 & 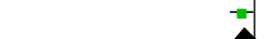 & & \\
\hline Subtotal (95\% Cl) & & & 49 & & & 51 & $57.9 \%$ & $-0.86[-2.05,0.32]$ & & & & \\
\hline \multirow{2}{*}{\multicolumn{13}{|c|}{$\begin{array}{l}\text { Heterogeneity: } \text { Tau }^{2}=0.21 ; \mathrm{Chi}^{2}=3.36, \mathrm{df}=3(P=0.34) ; \mathrm{I}^{2}=11 \% \\
\text { Test for overall effect: } Z=1.43(P=0.15)\end{array}$}} \\
\hline & & & & & & & & & & & & \\
\hline \multicolumn{13}{|l|}{ 1.1.2 Others } \\
\hline Park (2003) & -4.7 & 2.6 & 10 & 0.6 & 1.3 & 10 & $19.9 \%$ & $-5.30[-7.10,-3.50]$ & 2003 & $-\square$ & & \\
\hline Arslan (2011) & -2.7 & 3.1 & 29 & 0.3 & 2 & 20 & $21.6 \%$ & $-3.00[-4.43,-1.57]$ & 2011 & -- & & \\
\hline $\begin{array}{l}\text { Melam (2016) } \\
\text { Subtotal }(95 \% \mathrm{Cl})\end{array}$ & -5.1 & 31.4 & $\begin{array}{l}15 \\
54\end{array}$ & -0.7 & 26.5 & $\begin{array}{l}15 \\
45\end{array}$ & $\begin{array}{r}0.7 \% \\
42.1 \%\end{array}$ & $\begin{array}{r}-4.40[-25.19,16.39] \\
-4.06[-5.98,-2.14]\end{array}$ & 2016 & $\leftarrow$ & & \\
\hline \multicolumn{13}{|c|}{$\begin{array}{l}\text { Heterogeneity: } \mathrm{Tau}^{2}=1.26 ; \mathrm{Chi}^{2}=3.85, \mathrm{df}=2(P=0.15) ; \mathrm{I}^{2}=48 \% \\
\text { Test for overall effect: } Z=4.15(P<0.0001)\end{array}$} \\
\hline Total $(95 \% \mathrm{Cl})$ & & & 103 & & & 96 & $100.0 \%$ & $-1.97[-3.72,-0.23]$ & & & & \\
\hline \multicolumn{10}{|c|}{$\begin{array}{l}\text { Heterogeneity: } \mathrm{Tau}^{2}=3.13 ; \mathrm{Ch}^{2}=21.82, \mathrm{df}=6(P=0.001) ; \mathrm{I}^{2}=73 \% \\
\text { Test for overall effect: } Z=2.22(\mathrm{P}=0.03) \\
\text { Test for subaroub differences: } \mathrm{Chi}^{2}=7.72 . \mathrm{df}=1(\mathrm{P}=0.005), \mathrm{I}^{2}=87.0 \%\end{array}$} & $\begin{array}{lll}-20 & -10 & 0\end{array}$ & $\begin{array}{c}10 \\
\text { Favours [control] }\end{array}$ & 20 \\
\hline
\end{tabular}

Figure 2. Assessment of the effect of various types of aerobics on body weight. 


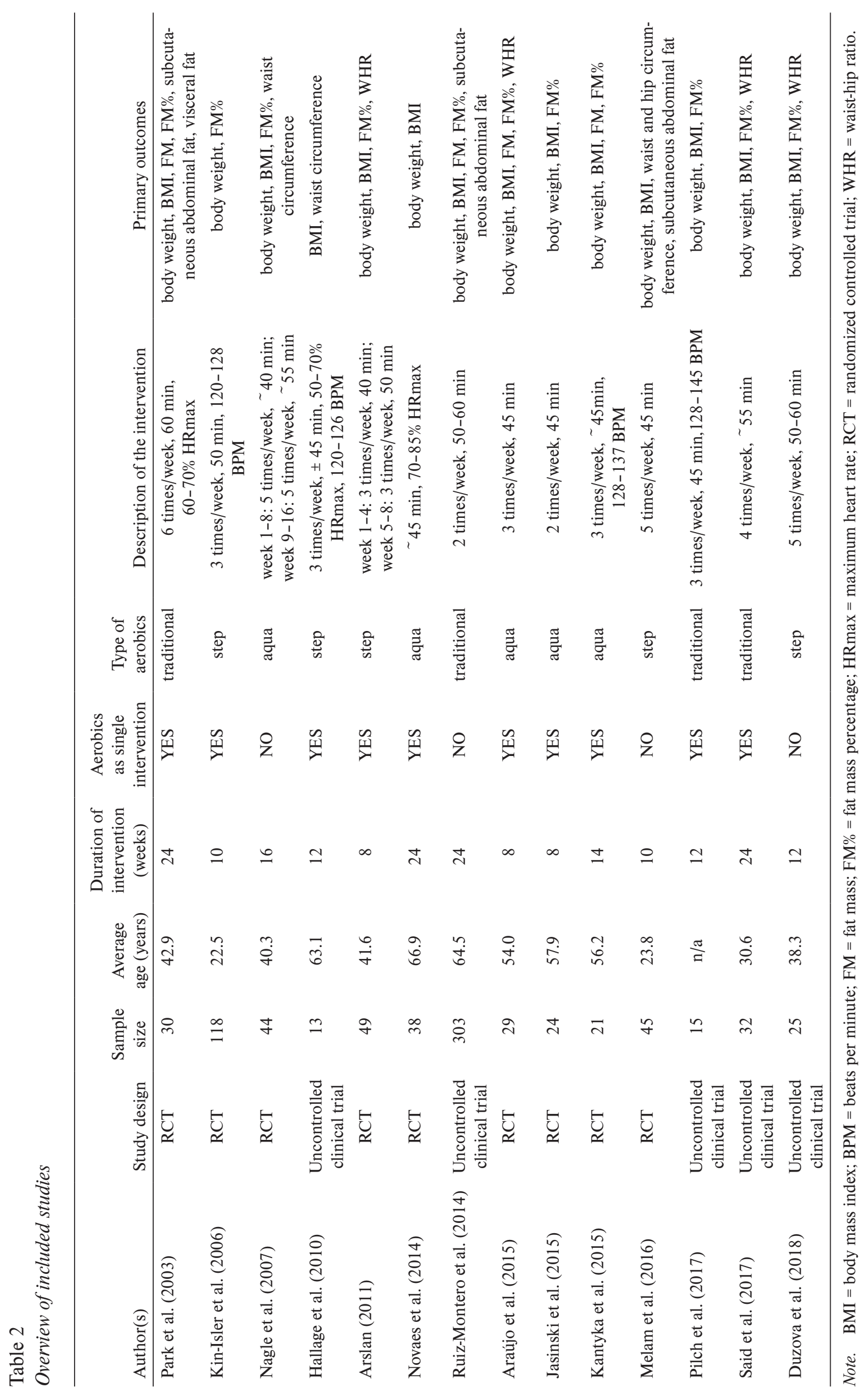


suggest a statistically significant effect. This group of studies was homogeneous $\left(I^{2}=11 \%\right)$, but the effect was $-0.86 \mathrm{~kg}(95 \% \mathrm{CI}[-2.05,0.32], p=.15)$. On the contrary, interventions using traditional and step AE suggested a significant weight loss by $4.06 \mathrm{~kg}$ (95\% CI $\left.[-5.98,-2.14], p<.001, I^{2}=48 \%\right)$. The effect of AE on $\mathrm{FM} \%$ is shown in Figure 3. The overall effect was $-2.62 \%$ (95\% CI [-5.53, 0.29], $p=.08)$; heterogeneity between studies was relatively high $\left(I^{2}=90 \%\right)$, which led to different results of the meta-analysis when the type of AE was considered. While the FM loss was negligible in aqua $\mathrm{AE}$ interventions, in other $\mathrm{AE}$ types $\mathrm{FM}$ was reduced by $6.59 \%$. However, this analysis did not suggest a significant effect either, particularly due to the high heterogeneity of the studies (95\% CI [-16.00, $\left.2.81], p=.17, I^{2}=97 \%\right)$.

In terms of the duration of intervention, it is clear that longer interventions are more effective (Figure 4 and 5). A greater effect was observed in interventions longer than 10 weeks, which resulted in a decrease in body weight by $2.61 \mathrm{~kg}(95 \%$ CI [-5.29, 0.07], $\left.p=.06, I^{2}=86 \%\right)$ and FM by $4.66 \%$ (95\% CI [-11.14, $\left.1.81], \quad p=.16 ; I^{2}=95 \%\right)$. Heterogeneity between studies shorter than 10 weeks was considerably lower ( $I^{2}<60 \%$ ), but their significant effect on body weight or FM\% was not confirmed.

\section{Discussion}

The present systematic review including a meta-analysis presents the results concerning the effect of intervention programmes with $\mathrm{AE}$ as a single or combined intervention on weight FM loss in adult women. The study is a synthesis of 14 primary studies published since 2000 found in the Medline and SPORTDiscus databases. The pooled sample for all studies was 756 females, 398 of whom participated in RCTs. To assess

\begin{tabular}{|c|c|c|c|c|c|c|c|c|c|c|}
\hline \multirow{2}{*}{$\frac{\text { Study or Subgroup }}{1.6 .1 \text { Aqua aerobic }}$} & \multicolumn{3}{|c|}{ Experimental } & \multicolumn{3}{|c|}{ Control } & \multicolumn{2}{|r|}{ Mean Difference } & \multicolumn{2}{|c|}{$\begin{array}{l}\text { Mean Difference } \\
\text { IV, Random, } 95 \% \mathrm{Cl}[\%]\end{array}$} \\
\hline & & & & & & & & & & \\
\hline Nagle (2007) & -5.7 & 3.4 & 22 & -6.5 & 5.5 & 22 & $16.8 \%$ & $0.80[-1.90,3.50] 2007$ & & \\
\hline Jasinski (2015) & 0.5 & 3.2 & 8 & 0.2 & 1 & 8 & $17.4 \%$ & $0.30[-2.02,2.62] 2015$ & & \\
\hline Kantyka (2015) & -2 & 2.6 & 10 & 1.4 & 2.6 & 11 & $17.6 \%$ & $-3.40[-5.63,-1.17] 2015$ & & \\
\hline $\begin{array}{l}\text { Araújo (2015) } \\
\text { Subtotal }(95 \% \mathrm{Cl})\end{array}$ & 0.6 & 4.5 & $\begin{array}{r}9 \\
49\end{array}$ & 0.4 & 6.2 & $\begin{array}{l}10 \\
51\end{array}$ & $\begin{array}{l}12.7 \% \\
64.6 \%\end{array}$ & $\begin{array}{l}0.20[-4.64,5.04] 2015 \\
-0.70[-2.92,1.53]\end{array}$ & & \\
\hline \multicolumn{11}{|c|}{$\begin{array}{l}\text { Heterogeneity: } \mathrm{Tau}^{2}=3.00 ; \mathrm{Chi}^{2}=7.59, \mathrm{df}=3(\mathrm{P}=0.06) ; \mathrm{I}^{2}=60 \% \\
\text { Test for overall effect: } Z=0.61(\mathrm{P}=0.54)\end{array}$} \\
\hline \multicolumn{11}{|l|}{ 1.6.2 Others } \\
\hline Park (2003) & -9.2 & 4.3 & 10 & 2.3 & 2.2 & 10 & $16.3 \%$ & $-11.50[-14.49,-8.51] 2003$ & & \\
\hline $\begin{array}{l}\text { Arslan (2011) } \\
\text { Subtotal (95\% Cl) }\end{array}$ & -1.8 & 2.8 & $\begin{array}{l}29 \\
39\end{array}$ & 0.1 & 0.1 & $\begin{array}{l}20 \\
30\end{array}$ & $\begin{array}{l}19.2 \% \\
35.4 \%\end{array}$ & $\begin{array}{l}-1.90[-2.92,-0.88] 2011 \\
-6.59[-16.00,2.81]\end{array}$ & -- & \\
\hline \multicolumn{11}{|c|}{$\begin{array}{l}\text { Heterogeneity: } \mathrm{Tau}^{2}=44.78 ; \mathrm{Ch}^{2}=35.39, \mathrm{df}=1(P<0.00001) ;\left.\right|^{2}=97 \% \\
\text { Test for overall effect: } Z=1.37(P=0.17)\end{array}$} \\
\hline Total $(95 \% \mathrm{Cl})$ & & & 88 & & & 81 & $100.0 \%$ & $-2.62[-5.53,0.29]$ & & \\
\hline \multicolumn{9}{|c|}{$\begin{array}{l}\text { Heterogeneity: } \mathrm{Tau}^{2}=11.25 ; \mathrm{Ch}^{2}=48.65, \mathrm{df}=5(\mathrm{P}<0.00001) ; \mathrm{I}^{2}=90 \% \\
\text { Test for overall effect: } Z=1.76(\mathrm{P}=0.08) \\
\text { Test for subaroup differences: } \mathrm{Ch}^{2}=1.43 . \mathrm{df}=1(\mathrm{P}=0.23) . \mathrm{I}^{2}=30.0 \%\end{array}$} & $\begin{array}{ccc}-1 & 1 & 1 \\
\text { Favours [experimental] } & 0\end{array}$ & $\begin{array}{lrr}0 & 5 & 10 \\
\text { Favours [control] }\end{array}$ \\
\hline
\end{tabular}

Figure 3. Assessment of the effect of various types of aerobics on fat mass percentage.

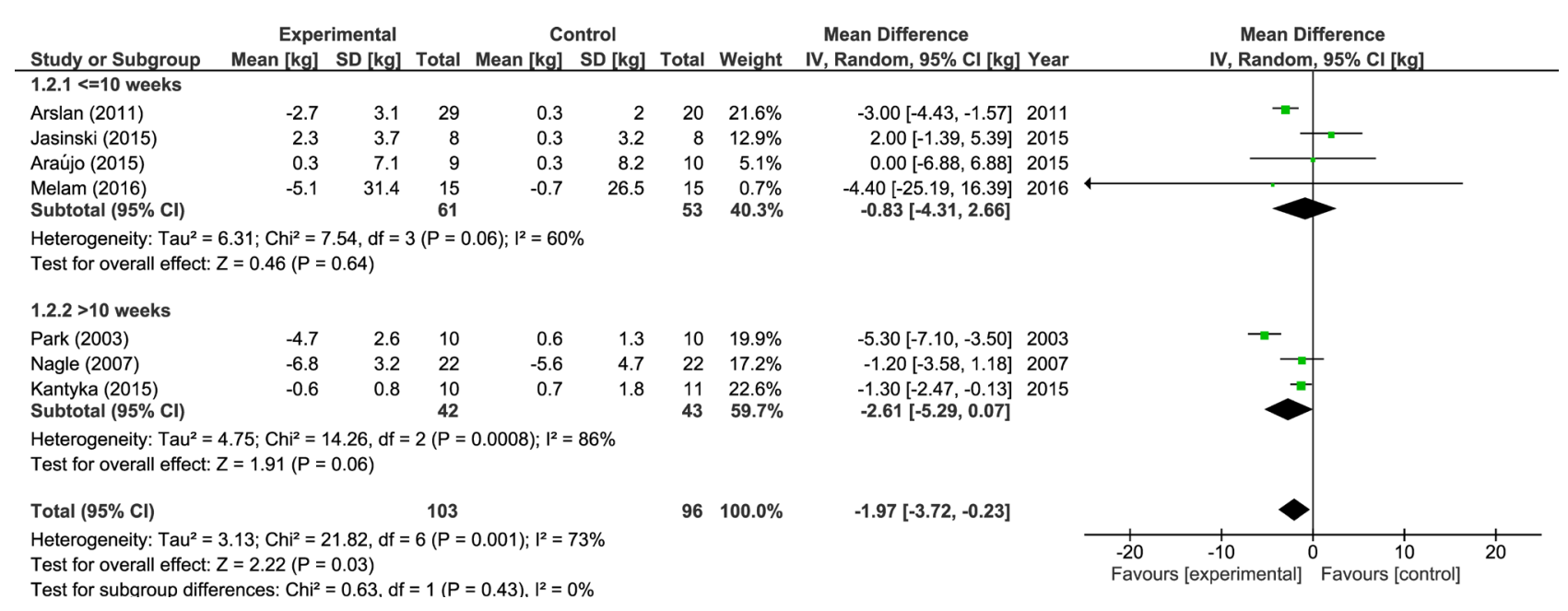

Figure 4. Assessment of the effect of aerobics on body weight depending on duration of intervention. 


\begin{tabular}{|c|c|c|c|c|c|c|c|c|c|c|c|c|}
\hline \multirow{2}{*}{$\begin{array}{l}\text { Study or Subgroup } \\
1.8 .1<=10 \text { weeks }\end{array}$} & \multicolumn{3}{|c|}{ Experimental } & \multicolumn{3}{|c|}{ Control } & \multicolumn{3}{|c|}{ Mean Difference } & \multicolumn{3}{|c|}{$\begin{array}{c}\text { Mean Difference } \\
\text { IV, Random, } 95 \% \mathrm{Cl}[\%]\end{array}$} \\
\hline & & & & & & & & & & & & \\
\hline Arslan (2011) & -1.8 & 2.8 & 29 & 0.1 & 0.1 & 20 & $19.2 \%$ & $-1.90[-2.92,-0.88]$ & 2011 & $\rightarrow-$ & & \\
\hline Jasinski (2015) & 0.5 & 3.2 & 8 & 0.2 & 1 & 8 & $17.4 \%$ & $0.30[-2.02,2.62]$ & 2015 & & & \\
\hline $\begin{array}{l}\text { Araújo }(2015) \\
\text { Subtotal }(95 \% \mathrm{Cl})\end{array}$ & 0.6 & 4.5 & $\begin{array}{r}9 \\
46\end{array}$ & 0.4 & 6.2 & $\begin{array}{l}10 \\
38\end{array}$ & $\begin{array}{l}12.7 \% \\
49.3 \%\end{array}$ & $\begin{array}{r}0.20[-4.64,5.04] \\
-1.01[-2.67,0.64]\end{array}$ & 2015 & & & \\
\hline \multicolumn{13}{|c|}{ Heterogeneity: $\mathrm{Tau}^{2}=0.93 ; \mathrm{Chi}^{2}=3.37, \mathrm{df}=2(\mathrm{P}=0.19) ; \mathrm{I}^{2}=41 \%$} \\
\hline \multicolumn{13}{|l|}{ 1.8.2 >10 weeks } \\
\hline Park (2003) & -9.2 & 4.3 & 10 & 2.3 & 2.2 & 10 & $16.3 \%$ & $-11.50[-14.49,-8.51]$ & 2003 & & & \\
\hline Nagle (2007) & -5.7 & 3.4 & 22 & -6.5 & 5.5 & 22 & $16.8 \%$ & $0.80[-1.90,3.50]$ & 2007 & & & \\
\hline $\begin{array}{l}\text { Kantyka }(2015) \\
\text { Subtotal }(95 \% \mathrm{Cl})\end{array}$ & -2 & 2.6 & $\begin{array}{l}10 \\
42\end{array}$ & 1.4 & 2.6 & $\begin{array}{l}11 \\
43\end{array}$ & $\begin{array}{l}\mathbf{1 7 . 6 \%} \\
\mathbf{5 0 . 7 \%}\end{array}$ & $\begin{array}{r}-3.40[-5.63,-1.17] \\
-4.66[-11.14,1.81]\end{array}$ & 2015 & & & \\
\hline \multicolumn{13}{|c|}{$\begin{array}{l}\text { Heterogeneity: } \mathrm{Tau}^{2}=30.89 ; \mathrm{Chi}^{2}=36.48, \mathrm{df}=2(\mathrm{P}<0.00001) ;\left.\right|^{2}=95 \% \\
\text { Test for overall effect: } Z=1.41(P=0.16)\end{array}$} \\
\hline Total $(95 \% \mathrm{Cl})$ & & & 88 & & & 81 & $100.0 \%$ & $-2.62[-5.53,0.29]$ & & & & \\
\hline \multicolumn{10}{|c|}{$\begin{array}{l}\text { Heterogeneity: } \mathrm{Tau}^{2}=11.25 ; \mathrm{Chi}^{2}=48.65, \mathrm{df}=5(\mathrm{P}<0.00001) ; \mathrm{I}^{2}=90 \% \\
\text { Test for overall effect: } Z=1.76(P=0.08) \\
\text { Test for subaroup differences: } \mathrm{Chi}^{2}=1.14, \mathrm{df}=1(\mathrm{P}=0.28) . \mathrm{I}^{2}=12.6 \%\end{array}$} & $\begin{array}{ccc}-10 & -5 \\
\text { Favours [experimental] }\end{array}$ & $\begin{array}{ll} & 5 \\
0 & 5 \\
\text { Favours [col }\end{array}$ & \\
\hline
\end{tabular}

Figure 5. Assessment of the effect of aerobics on fat mass percentage depending on duration of intervention.

the overall effect of AE on weight and FM loss, 7 RCTs were used, the results of which suggest that traditional $\mathrm{AE}$ and interventions longer than 10 weeks have a greater effect compared with interventions including aqua $\mathrm{AE}$ or interventions shorter than 10 weeks.

The majority of the studies combined various female participants in their intervention programmes, which was probably the cause of certain heterogeneity of the participants. The participants in the interventions were marked by a high degree of variability regarding their age and health status. Probably, for this reason, aqua $\mathrm{AE}$ was the most frequently used type of $\mathrm{AE}$. Due to its safety and lower intensity, this type of $\mathrm{AE}$ is also frequently used by the oldest age group of women. On the contrary, in younger age categories, step AE was more popular compared with traditional AE.

The results presented in this paper suggest that interventions longer than 10 weeks are more effective compared with shorter interventions. One of the limitations of longer interventions is their time demanding nature and related lower participant adherence and higher drop-out (van der Bij, Laurant, \& Wensing, 2002). In the evaluation of the results, it is also important to consider the effect of the interventions with respect to various types of $\mathrm{AE}$. Aqua $\mathrm{AE}$ had no effect on body weight and $\mathrm{FM} \%$, while a positive effect on weight loss was confirmed for step and traditional AE. Aqua $\mathrm{AE}$ is suitable especially for overweight individuals due to the aquatic environment. Women feel more comfortable in an aquatic environment and in the presence of other female participants (Claesson et al., 2008).

The reason why aqua $\mathrm{AE}$ did not provide the desired effect on body weight and $\mathrm{FM} \%$ can be for example the low intensity or low frequency of the exercise. The average duration of a lesson in the studies involved was 45-50 minutes, which meets the minimum recommended lesson duration. However, when the exercise was involved only twice or three times a week, the participants achieved the lower limit of the recommended PA duration per week. Unless the intervention includes dietary restrictions, and none of the studies using aqua $\mathrm{AE}$ did, positive results cannot be expected. Studies that combine PA with dietary restrictions have a greater positive effect on the body composition of individuals included in the intervention (Andrews et al., 2011; Claesson et al., 2008). A study by Swift, Johannsen, Lavie, Earnest, and Church (2014) suggests the significance of a dietary restriction. The authors concluded that the results of overweight and obese individuals who take part in an intervention including only a certain type of PA are heterogeneous and mostly do not achieve the desired weight loss. Overweight and obese individuals who wish to decrease their weight and especially FM\% must combine their PA intervention with a dietary restriction, which clearly leads to better results.

In the evaluation of the results, the quality of the studies involved must be considered. The Cochrane Collaboration Risk of Bias Tool suggests that the risk of bias concerning the results of the studies included in the meta-analyses is relatively high. The main cause is the absence of information to assess the selection, performance and attrition bias. The methodological quality of the studies is demonstrated by the fact that none of the studies was designed according to the CONSORT statement or a similar recommendation. Despite the fact that in all studies involved the participants were randomly divided into groups, none of the studies described a random component in the sequence generation. Moreover, none of the studies described a method of concealment or gave reasons for the missing data. None of the studies provided a study protocol; however, it is clear that the published reports included all expected outcomes. 


\section{Conclusions}

The results suggest that $\mathrm{AE}$ can be a suitable method for weight and FM loss in adult women. It was confirmed that traditional $\mathrm{AE}$ and step $\mathrm{AE}$ had a greater effect on weight loss, while aqua $\mathrm{AE}$ did not bring a statistically significant effect. It was also confirmed that interventions longer than 10 weeks were more effective compared with shorter interventions. However, this finding must be interpreted with caution, especially with respect to the high variability of the effect of primary studies and a potentially high risk of bias based on the absence of relevant information that could be used to assess the risk of bias.

\section{Conflict of interest}

There were no conflicts of interest.

\section{References}

References marked with an asterisk indicate studies included in the meta-analysis.

Andrews, R. C., Cooper, A. R., Montgomery, A. A., Norcross, A. J., Peters, T. J., Sharp, D. J., ... Dayan, C. M. (2011). Diet or diet plus physical activity versus usual care in patients with newly diagnosed type 2 diabetes: The Early ACTID randomised controlled trial. Lancet, 378, 129-139.

Angrisani, L., Santonicola, A., Iovino, P., Formisano, G., Buchwald, H., \& Scopinaro, N. (2015). Bariatric surgery worldwide 2013. Obesity Surgery, 25, 1822-1832.

*Araújo, J. P., Neto, G. R., Silva, J., Silva, H. G., Neto, E. A. P., Batista, G. R., ... Cirilo-Sousa, M. d. S. (2015). Does water aerobics with blood flow restriction change the body composition? Journal of Exercise Physiology Online, 18, 25-31.

*Arslan, F. (2011). The effects of an eight-week step-aerobic dance exercise programme on body composition parameters in middle-aged sedentary obese women. International SportsMed Journal, 12, 160-168.

Ball, K., Owen, N., Salmon, J., Bauman, A., \& Gore, C. J. (2001). Associations of physical activity with body weight and fat in men and women. International Journal of Obesity and Related Metabolic Disorders, 25, 914-919.

Blair, S. N., \& Church, T. S. (2004). The fitness, obesity, and health equation: Is physical activity the common denominator? JAMA, 292, 1232-1234.

Caballero, B. (2007). The global epidemic of obesity: An overview. Epidemiologic Reviews, 29, 1-5.

Claesson, I. M., Josefsson, A., Cedergren, M., Brynhildsen, J., Jeppsson, A., Nystrom, F., ... Sydsjo, G. (2008). Consumer satisfaction with a weight-gain intervention programme for obese pregnant women. Midwifery, 24, 163-167.

Donnelly, J. E., Blair, S. N., Jakicic, J. M., Manore, M. M., Rankin, J. W., \& Smith, B. K. (2009). American College of Sports Medicine Position Stand. Appropriate physical activity intervention strategies for weight loss and prevention of weight regain for adults. Medicine \& Science in Sports \& Exercise, 41, 459-471.

Donnelly, J. E., Hill, J. O., Jacobsen, D. J., Potteiger, J., Sullivan, D. K., Johnson, S. L., ... Washburn, R. A. (2003). Effects of a 16-month randomized controlled exercise trial on body weight and composition in young, overweight men and women: The Midwest Exercise Trial. Archives of Internal Medicine, 163, 1343-1350.

Duzova, H., Gullu, E., Cicek, G., Koksal, B. K., Kayhan, B., Gullu, A., \& Sahin, I. (2018). The effect of exercise induced weight-loss on myokines and adipokines in overweight sedentary females: Steps-aerobics vs. joggingwalking exercises. Journal of Sports Medicine and Physical Fitness, 58, 295-308.

Esposito, K., Pontillo, A., Di Palo, C., Giugliano, G., Masella, M., Marfella, R., \& Giugliano, D. (2003). Effect of weight loss and lifestyle changes on vascular inflammatory markers in obese women: A randomized trial. JAMA, 289, 1799-1804.

Ewald, B., Attia, J., \& McElduff, P. (2014). How many steps are enough? Dose-response curves for pedometer steps and multiple health markers in a community-based sample of older Australians. Journal of Physical Activity and Health, 11, 509-518.

Finucane, M. M., Stevens, G. A., Cowan, M. J., Danaei, G., Lin, J. K., Paciorek, C. J., ... Ezzati, M. (2011). National, regional, and global trends in body-mass index since 1980: Systematic analysis of health examination surveys and epidemiological studies with 960 country-years and 9.1 million participants. Lancet, 377, 557-567.

Fogelholm, M., \& Kukkonen-Harjula, K. (2000). Does physical activity prevent weight gain - a systematic review. Obesity Reviews, 1, 95-111.

Frank, L. D., Andresen, M. A., \& Schmid, T. L. (2004). Obesity relationships with community design, physical activity, and time spent in cars. American Journal of Preventive Medicine, 27, 87-96.

Gappmaier, E., Lake, W., Nelson, A. G., \& Fisher, A. G. (2006). Aerobic exercise in water versus walking on land: Effects on indices of fat reduction and weight loss of obese women. Journal of Sports Medicine and Physical Fitness, 46, 564-569.

Hallage, T., Krause, M. P., Haile, L., Miculis, C. P., Nagle, E. F., Reis, R. S., \& Da Silva, S. G. (2010). The effects of 12 weeks of step aerobics training on functional fitness of elderly women. Journal of Strength and Conditioning Research, 24, 2261-2266.

Higgins, J. P., Thompson, S. G., Deeks, J. J., \& Altman, D. G. (2003). Measuring inconsistency in meta-analyses. BMJ, $327,557-560$.

Hu, F. B. (2003). Overweight and obesity in women: Health risks and consequences. Journal of Women's Health, 12, 163-172.

Jakicic, J. M., \& Otto, A. D. (2005). Physical activity considerations for the treatment and prevention of obesity. American Journal of Clinical Nutrition, 82(1 Suppl), 226s-229s.

*Jasiński, R., Socha, M., Sitko, L., Kubicka, K., Sobiech, M. W. K. A., \& Sobiech, K. A. (2015). Effect of nordic walking and water aerobics training on body composition 
and the blood flow in lower extremities in elderly women. Journal of Human Kinetics, 45, 113-122.

*Kantyka, J., Herman, D., Roczniok, R., \& Kuba, L. (2015). Effects of aqua aerobics on body composition, body mass, lipid profile, and blood count in middle-aged sedentary women. Human Movement, 16, 9-14.

Kay, S. J., \& Fiatarone Singh, M. A. (2006). The influence of physical activity on abdominal fat: A systematic review of the literature. Obesity Reviews, 7, 183-200.

Kin-Isler, A., \& Kosar, S. N. (2006). Effect of step aerobics training on anaerobic performance of men and women. Journal of Strength and Conditioning Research, 20, 366-371.

Li, M., \& Cheung, B. M. Y. (2009). Pharmacotherapy for obesity. British Journal of Clinical Pharmacology, 68, 804-810.

*Melam, G. R., Alhusaini, A. A., Buragadda, S., Kaur, T., \& Khan, I. A. (2016). Impact of brisk walking and aerobics in overweight women. Journal of Physical Therapy Science, 28, 293-297.

Moher, D., Liberati, A., Tetzlaff, J., \& Altman, D. G. (2009). Preferred reporting items for systematic reviews and metaanalyses: The PRISMA statement. PLOS Medicine, 6, e1000097.

*Nagle, E. F., Robertson, R. J., Jakicic, J. J., Otto, A. D., Ranalli, J. R., \& Chiapetta, L. B. (2007). Effects of aquatic exercise and walking in sedentary obese women undergoing a behavioral weight-loss intervention. International Journal of Aquatic Research and Education, 1, 43-56.

Ng, M., Fleming, T., Robinson, M., Thomson, B., Graetz, N., Margono, C., ... Gakidou, E. (2014). Global, regional, and national prevalence of overweight and obesity in children and adults during 1980-2013: A systematic analysis for the Global Burden of Disease Study 2013. Lancet, 384, 766-781.

Novaes, G. S., Novaes, J. S., Vilaça-Alves, J., Costa e Silva, G., Garrido, N. D., Furtado, H., \& Reis, V. M. (2014). Chronic effects of strength training vs. hydro aerobics on functional and cardiorespiratory ability in postmenopausal women. Journal of Human Kinetics, 43, 57-66.

*Park, S. K., Park, J. H., Kwon, Y. C., Kim, H. S., Yoon, M. S., \& Park, H. T. (2003). The effect of combined aerobic and resistance exercise training on abdominal fat in obese middle-aged women. Journal of Physiological Anthropology and Applied Human Science, 22, 129-135.
Petersen, L., Schnohr, P., \& Sorensen, T. I. (2004). Longitudinal study of the long-term relation between physical activity and obesity in adults. International Journal of Obesity and Related Metabolic Disorders, 28, 105-112.

Pilch, W., Tota, L., Sadowska-Krepa, E., Piotrowska, A., Kepinska, M., Palka, T., \& Maszczyk, A. (2017). The effect of a 12-week health training program on selected anthropometric and biochemical variables in middle-aged women. BioMed Research International, 2017, 9569513.

Ruiz-Montero, P. J., Castillo-Rodriguez, A., Mikalacki, M., Nebojsa, C., \& Korovljev, D. (2014). 24-weeks Pilatesaerobic and educative training to improve body fat mass in elderly Serbian women. Clinical Interventions in Aging, 9, 243-248.

Said, M., Lamya, N., Olfa, N., \& Hamda, M. (2017). Effects of high-impact aerobics vs. low-impact aerobics and strength training in overweight and obese women. Journal of Sports Medicine and Physical Fitness, 57, 278-288.

Swift, D. L., Johannsen, N. M., Lavie, C. J., Earnest, C. P., \& Church, T. S. (2014). The role of exercise and physical activity in weight loss and maintenance. Progress in Cardiovascular Diseases, 56, 441-447.

Swinburn, B. A., Kraak, V. I., Allender, S., Atkins, V. J., Baker, P. I., Bogard, J. R., ... Dietz, W. H. (2019). The Global Syndemic of Obesity, Undernutrition, and Climate Change: The Lancet Commission report. Lancet, 393, 791-846.

Tanofsky-Kraff, M., Wilfley, D. E., Young, J. F., Mufson, L., Yanovski, S. Z., Glasofer, D. R., ... Schvey, N. A. (2010). A pilot study of interpersonal psychotherapy for preventing excess weight gain in adolescent girls at-risk for obesity. International Journal of Eating Disorders, 43, 701-706.

van der Bij, A. K., Laurant, M. G., \& Wensing, M. (2002). Effectiveness of physical activity interventions for older adults: Review. American Journal of Preventive Medicine, 22, 120-133.

Wadden, T. A., Berkowitz, R. I., Womble, L. G., Sarwer, D. B., Phelan, S., Cato, R. K., ... Stunkard, A. J. (2005). Randomized trial of lifestyle modification and pharmacotherapy for obesity. New England Journal of Medicine, 353, 2111-2120.

Wing, R. R., \& Phelan, S. (2005). Long-term weight loss maintenance. American Journal of Clinical Nutrition, 82(1 Suppl), 222s-225s. 